\title{
Hipótesis de Investigación
}

\author{
Research hypothesis
}

Sandra Luz Hernández, Mendoza ${ }^{a}$, Danae Duana Avila ${ }^{b}$

\begin{abstract}
:
In the presence of any problem or mystery, every person can suppose, suspect and look for possible explanations. We call these hypotheses, which is considered as a supposition that expresses the possible relationship between two or more variables and is formulated to respond tentatively to a problem or research question. So, the hypothesis implies a series of factors, it must be conceptually clear, it must not lead to moral judgments, it must be specific, it must be expressed in a specific and not general way and be related to the available techniques, to be tested.
\end{abstract}

\section{Keywords:}

Variables, problem, research.

\section{Resumen:}

Ante la presencia de cualquier problema o incógnita toda persona esta en capacidad de suponer, sospechar y de buscar posibles explicaciones. Tales conjeturas las llamamos hipótesis la cuál es considerada como una suposición que expresa la posible relación entre dos o más variables y se formula para responder tentativamente a un problema o pregunta de investigación. Así también la hipótesis implica una serie de factores, tiene que ser conceptualmente clara, no debe llevar a juicios morales, ha de ser específica, debe expresarse en una forma específica y no general y relacionarse con las técnicas disponibles, para someterse a prueba.

\section{Palabras Clave:}

Variables, problema, investigación

\section{Introducción}

La concepción de la hipótesis con lleva un conocimiento fundamental para el desarrollo de cualquier tipo de investigación. A través de la hipótesis se alcanzan los conocimientos científicos existentes con los nuevos problemas sugeridos en la realidad.

Las hipótesis orientan a la investigación e indican al investigador donde debe iniciar su labor de verificación o comprobación mediante la recolección de datos [1].

La formulación de hipótesis es necesaria en investigaciones de nivel explicativo, cuando se pretende establecer relaciones causales entre variables. También es pertinente el uso de hipótesis en algunas investigaciones de carácter descriptivo, específicamente las correlacionales y en las que se busca establecer la asociación (no causal) entre variables.

En las investigaciones de nivel exploratorio, debido al escaso conocimiento que se posee sobre el objeto de estudio, no se plantean hipótesis de forma explícita, es decir se trabaja sólo con objetivos. [2]

Si en una investigación no se verifica la hipótesis de trabajo, no significa que el estudio sea valido o que carezca de utilidad.

Así mismo mientras la formulación del problema adopta la forma interrogativa, las hipótesis se redacta de manera afirmativa, excepto la hipótesis nula, que niega la hipótesis de investigación.

a Profesor-Asignatura del Instituto de Ciencias Económico Administrativas. Universidad Autónoma del Estado de Hidalgo. Área Académica de Turismo-Campus ICEA., https://orcid.org/0000-0002-2022-3135, E-mail: sandrahm@uaeh.edu.mx

b Profesor-Investigador del Instituto de Ciencias Económico Administrativas. Universidad Autónoma del Estado de Hidalgo. Área académica de Administración--Campus ICEA, https://orcid.org/0000-0003-2286-2843 E-mail: duana@uaeh.edu.mx 
Para un buen planteamiento o redacción de la hipótesis es preciso:

- Evitar emplear adjetivos que impliquen juicios de valor, por ejemplo: bueno, malo, poco, mucho se sustituye por mayor, menor, alto, bajo etc.

- Incluir variables identificadas en la formulación del problema y en los objetivos específicos

- Pueden ser expresadas en términos conceptuales u operacionales

Por otra parte, es necesario identificar la relación entre el problema-hipótesis, esta consiste en que la hipótesis representa una posible respuesta a la formulación del problema o pregunta [3].

\section{Referencias}

[1] Fidias G. Arias (2006). El proyecto de investigación. Introducción a la metodología científica $6^{\circ}$ edición. Editorial Episteme

[2] Ávila Baray, H. L (2006) Introducción a la metodología de la investigación. Recuperado y consultado el 28 de junio de 2019 de:

https://clea.edu.mx/biblioteca/INTRODUCCION\%20A\%20LA\%2 OMETODOLOGIA\%20DE\%20LA\%2OINVESTIGACION.pdf

[3] Pájaro Huertas, D. (2002). La Formulación de Hipótesis. Cinta de Moebio, (15). Universidad de Chile. Recuperado y consultado el 26 de junio de 2019 de: http://www.redalyc.org/pdf/101/10101506.pdf

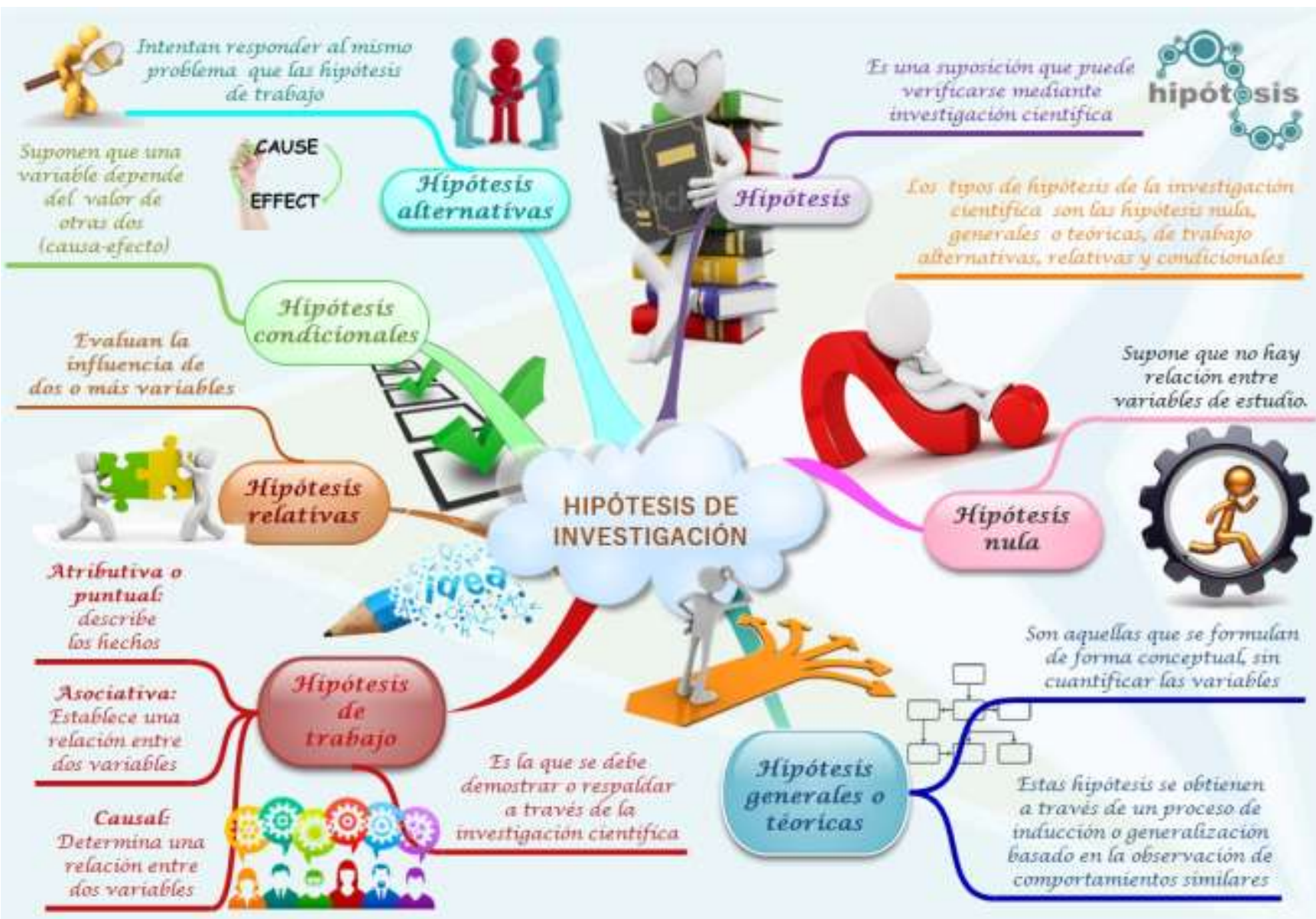

